\title{
Myocardial infarction during pregnancy: report of two cases with a review of the literature
}

\author{
M. H. HuSAINI \\ B.Sc., M.B., B.S., D.T.M. and H., T.D.D., M.R.C.P.(Edin.), M.R.C.P.(Lond.) \\ Crumpsall Hospital and The Royal Infirmary, Manchester
}

\section{Summary}

Two further cases of myocardial infarction during pregnancy are reported.

From the review of the literature of forty-three cases of myocardial infarction during pregnancy and labour, it appears that myocardial infarction in the last trimester and labour is frequently fatal.

Short-term anticoagulant therapy to suppress any thrombo-embolic tendency is desirable.

Termination of pregnancy is indicated for patients in cardiac failure or persistent angina. For patients who are well, either assisted vaginal delivery or Caesarean section are equally good.

\section{Introduction}

Myocardial infarction is uncommon in women of childbearing age (Weinreb, German \& Rosenberg, 1957; Oliver, 1970). In several reviews of heart disease during pregnancy myocardial infarction is only occasionally listed as a cause of heart disease (Hamilton, 1947; Jones, 1951; Mendelson, 1960; Rothe \& Schlawe, 1965; Mather, Abbas \& Mehta, 1966).

It is probable that some cases of shock or chest pain are misdiagnosed (Maternal Health in Ohio, 1958; Brown, 1960).

In this paper two patients are described who developed myocardial infarction during pregnancy.

\section{Case reports}

\section{Case 1}

H. M., age 40, was admitted under the care of Dr S. Oleesky on 6 August 1963, gravida three, para two, last menstrual period 1 May 1963. For 6 weeks she had been having pain in the left arm with a feeling of heaviness across the chest produced by climbing uphill, forcing her to stop, with relief in a couple of minutes. She had hypertension during the two previous pregnancies in 1954 and 1960, but

Correspondence: Dr M. H. Husaini, Senior Registrar, Cardiovascular Department, Newcastle General Hospital, Westgate Road, Newcastle on Tyne, NE4 6BE. after each pregnancy her blood pressure fell to 3 normal. There was no albuminuria during preg $-\bar{A}$ nancies.

On examination her blood pressure was 210/120 N $\mathrm{mmHg}$, otherwise no abnormality was detected. $)$ Haemoglobin, white cell count, blood urea and electrolytes, urinary catecholamines and 5-hydroxy-5 indoles, chest X-ray and ECG (Fig. 1) were normal. Three days later she developed sudden severe chest pain and appeared pale and shocked, with lowo volume pulse and BP 130/100 $\mathrm{mmHg}$; ECG noww showed evidence of inferior myocardial infarctign $\vec{c}$ with ST depression V3-V6. Serum glutamic ox - acetic transaminase (SGOT) was elevated to 190 and serum glutamic pyruvic transaminase (SGPT) Foo 92 units. Phenindione therapy was commenced. Her general condition improved, BP settling to $110 / 70$ o mmHg. Fourteen days after admission she had $a \stackrel{\infty}{\infty}$ recurrence of chest pain, and BP fell to $90 / 60 \mathrm{mmHg}$. Further ECG showed no evidence of a fresh ischae- $\overrightarrow{\overrightarrow{0}}$ mic episode. Subsequent progress was uneventful ${ }^{\exists}$ and she was discharged 1 month later on anticoagulant therapy. During follow-up she remained well. The serum cholesterol on 9 October 1963, was $365 \mathrm{mg} / 100 \mathrm{ml}$, BP $120 / 70 \mathrm{mmHg}$.

During the seventh month of gestation she was re-admitted with exertional dyspnoea, peripheralo. oedema and BP 170/95 mmHg. Anticoagulants were discontinued. There was little response to digoxin, diuretics, salt restriction and hypotensive 5 drugs, and the BP remained around $180 / 100 \mathrm{mmHg} . \frac{7}{0}$

On the 18 January 1964, a live infant was delivered by Caesarean section, with rapid relief of symptoms. $N$ Oedema resolved and BP fell to $110 / 80 \mathrm{mmHg}$. One week later she developed deep vein thrombosis of the N left leg, and phenindione was given for 5 weeks. $\omega$ One month after Caesarean section BP had risen to $150 / 95 \mathrm{mmHg}$. She was maintained on digoxin and $\stackrel{\circ}{=}$ diuretics as an out-patient. Three months post- $\stackrel{\Phi}{\mathcal{D}}$ partum she collapsed and died suddenly.

Necropsy (Dr Allison): the heart weight was $340 \mathrm{~g}$. $\frac{0}{0}$ There was no hypertrophy or dilatation of atria or $\overrightarrow{\mathbb{D}}$ 


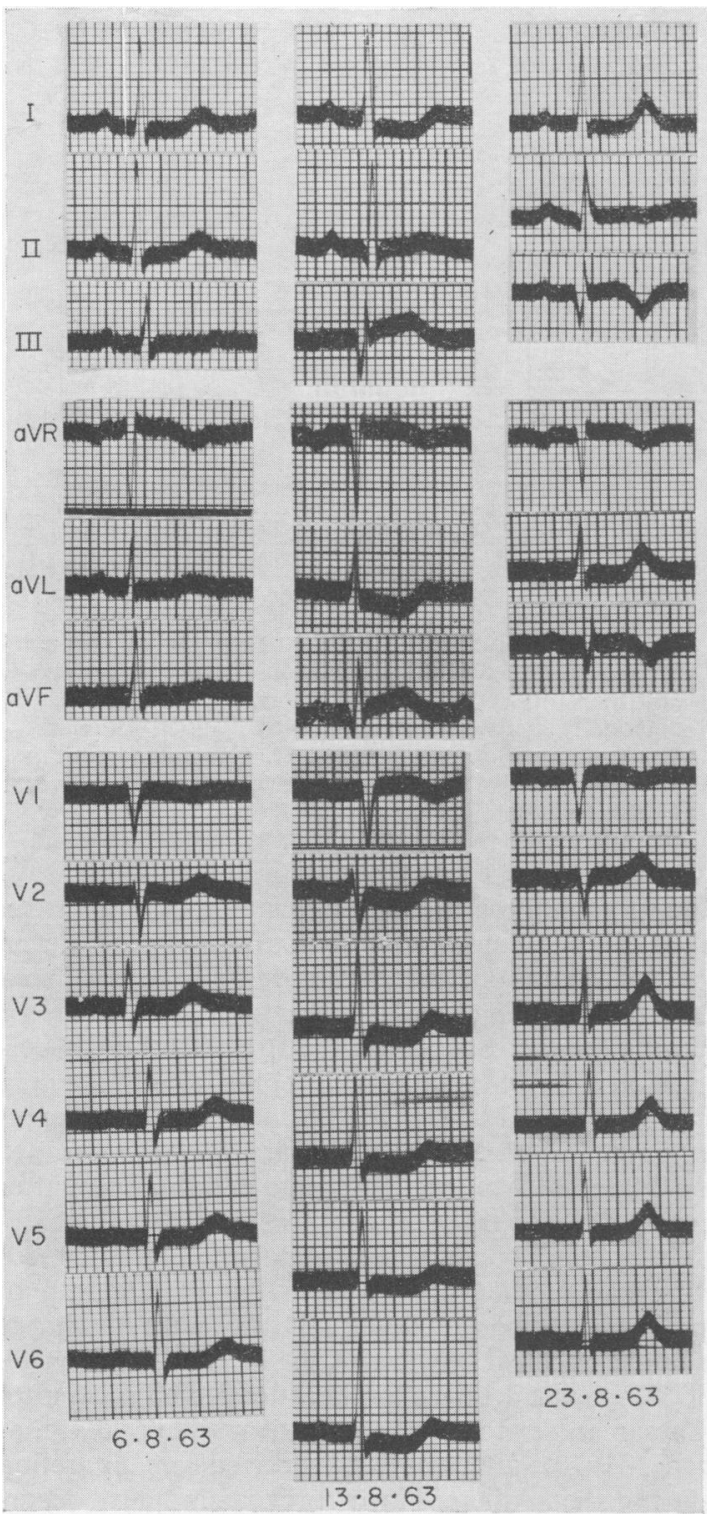

Fig. 1. ECG Case 1.

ventricles. Extensive coronary artery atheroma was present, with occlusion of the right coronary artery by calcified atheroma and several areas of narrowing of each of the main branches of the left coronary artery. No recent thrombosis was found. Atheroma was also present in the thoracic and abdominal aorta. Numerous cholesterol stones were present in the gall bladder.

Histology. Posterior wall of left ventricle replaced by fibrous tissue. No evidence of recent muscle necrosis. Recanalized occlusion of right coronary artery. Hypertensive changes were not seen in the renal arteries.

\section{Case 2}

J. D., age 32, was admitted under the care of Dr A. Morgan Jones on the 14 December 1966. Gravida four, para one, last menstrual period 8 April 1966. She had been depressed for some years and received diazepam $5 \mathrm{mg}$ t.d.s. intermittently. In November, she had an influenza-like illness, which increased her depression.

On the 19 December 1966, she felt hot, and then cold, with shivering and palpitations. She complained of a chest pain like a constant tightness under the sternum radiating to the back and associated with pain in the left arm. This persisted intermittently for a few days. She developed dyspnoea, cough and orthopnoea, but no paroxysmal nocturnal dyspnoea.

On examination her blood pressure was $120 / 70$ $\mathrm{mmHg}$, heart rate $110 / \mathrm{min}$, jugular venous pressure not raised. There was no oedema and no basal crepitations. ECG (Fig. 2) on 14 December 1966, showed inferolateral myocardial infarction. Other investigations on 14 December 1966, were: total WCC $11,200 / \mathrm{mm}^{3}$, differential normal, $\mathrm{Hb} 9 \cdot 8$ $\mathrm{g} / 100 \mathrm{ml}$, ESR $61 \mathrm{~mm}$ in first hour. Serum albumin $2.8 \mathrm{~g} / 100 \mathrm{ml}$, serum globulin $2.9 \mathrm{~g} / 100 \mathrm{ml}$, serum cholesterol $190 \mathrm{mg} / 100 \mathrm{ml}$, serum lactic acid dehydrogenase, SGOT, SGPT, bilirubin, alkaline phosphatase, thymol turbidity, blood urea and electrolytes normal. No lupus erythematosus cells detected. Antinuclear factor test was negative.

She was treated with bed rest and digoxin. On 27 December 1966, she had a normal spontaneous delivery of a live infant.

X-ray of chest after delivery showed prominent left cardiac border, but on fluoroscopy no aneurysmal changes were seen. She was discharged home well on 25 January 1967. Intermittent chest pains of atypical nature persisted post-partum.

She became pregnant again about the beginning of June 1967. In view of endogenous depression, previous infarction and frequent chest pains of indeterminate nature, therapeutic evacuation of the uterus and sterilization were carried out in the beginning of September 1967. Subsequently she continued to complain of vague symptoms but there was no heart failure and no enlargement of the heart.

In 1968 she was admitted with an attack of ventricular tachycardia which necessitated cardioversion. No fresh changes of cardiac infarction were discovered.

\section{Discussion}

Forty-three cases of proved myocardial infarction during pregnancy or labour have been reported in 


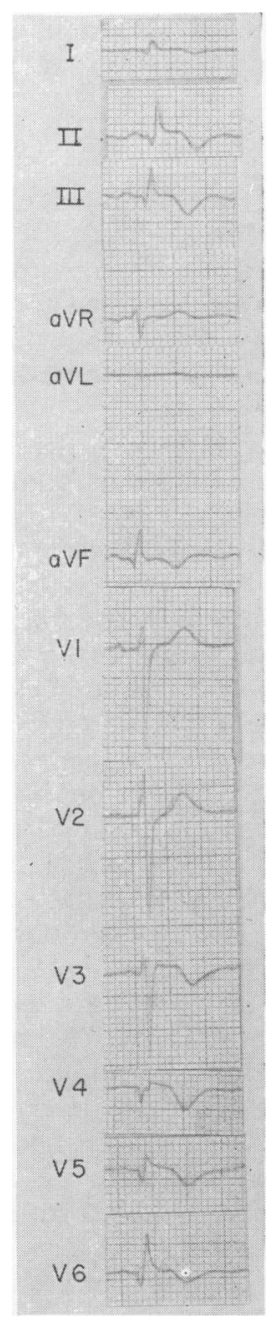

Fig. 2. ECG Case 2, 14 December 1966.

the world literature (Table 1). In addition, Gordon (1955) in a post-mortem series of 176 maternal deaths in Brooklyn found three cases of myocardial infarction; as no clinical details are available these cases have not been included in the Table. Three cases reported by Phillips (1962) and one case reported by Ginz (1970) are excluded from the discussion as neither the ECG not enzyme studies are recorded in the publications. Froehlich $(1963,1968)$ has reported one case of generalized $\mathrm{T}$-wave inversion in a pregnant woman who was admitted with a history of loss of consciousness and convulsions followed by purposeless movement of the left upper arm. This case is excluded because of uncertainty of diagnosis.

The month of gestation at the onset of cardiac infarction, the presence of hypertension, method of

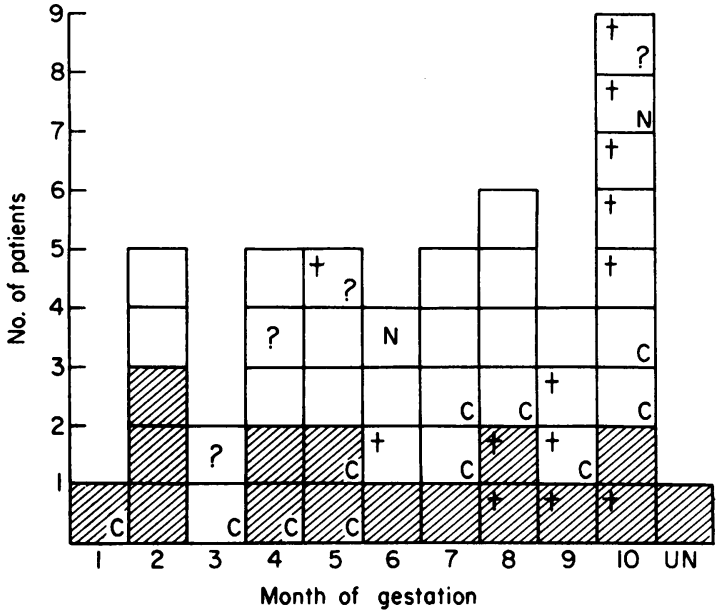

Fig. 3. The month of gestation at onset of cardiac infarction, presence of hypertension, method of delivery and mortality. Open columns, normal blood pressure; diagonally hatched columns, raised blood pressure; ?, blood pressure not known; C, Caesarean section; $\dagger$, did not survive; UN, month of gestation not known; $\mathrm{N}$, same patient-see text.

delivery and mortality are shown in Fig. 3. Thirteen died during pregnancy or soon after delivery, eleve of these deaths occurring amongst those who suffered infarction during the last months of pregnancy of? during labour. Sixteen of the forty-five had hypertension; four of these died, all of the latter sustaining cardiac infarction during the last months of pregnancy (Mendelson, 1952; Stewart, 1952; Committee on Maternal Welfare, 1957), and expiring soon after infarction. The blood pressure was normal in twentyfive. Seven of these died. One patient (Brown, 1960) who had cardiac infarction in the sixth month of pregnancy died at home, $24 \mathrm{hr}$ after discharge against medical advice. Another patient (Lynge, 1961) who had infarction near term died soon after Caesarean section. A third patient (Curry \& Quintana, 1970) after having survived an infarction during the sixth month of pregnancy had a recurrence during the tenth month and died (patient $\mathrm{N}$, Fig. 3). Four patients (Magner, 1961 ; Krawczuk \& Jakowicki, 1965; Pantev \& Piperkov, 1968) had cardiac infarction during labour and died rapidly with severe shock and pulmonary oedema. One other reported case of myocardial infarction during labour (Katz, 1922) died; the blood pressure of this patient is not known. The blood pressure of the patient who had cardiac infarction during the fifth month of pregnancy and died (Muir, 1960) is also not known.

The patient of Pantev \& Piperkov (1968) is interesting as infarction was considered to be due to 
TABLE 1. Reported cases of myocardial infarction during pregnancy showing age and important complications

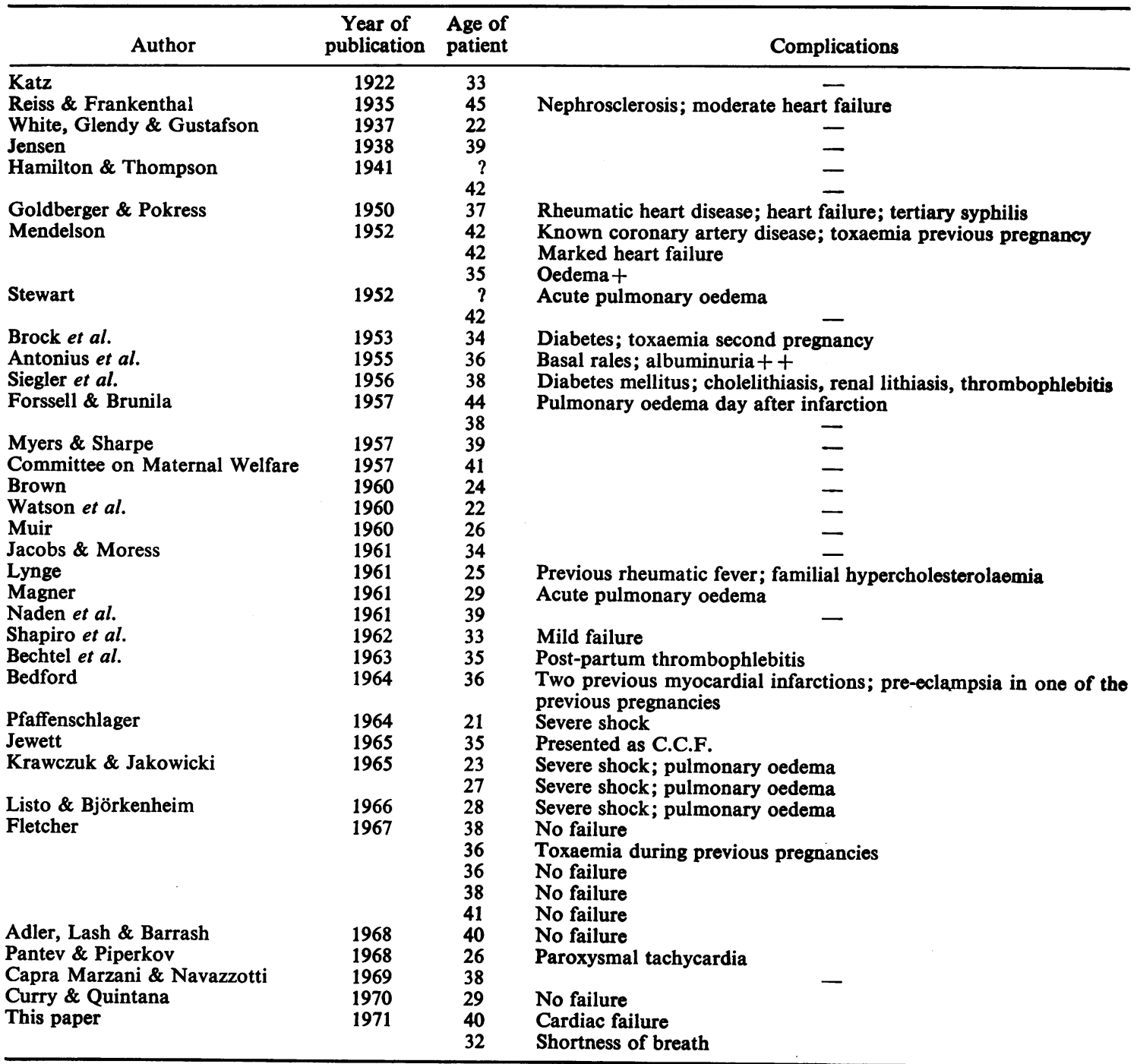

paroxysmal tachycardia. The coronary arteries were normal at necropsy.

\section{Sedation}

Adequate analgesic therapy is required. These drugs help reduce shock and with reasonable care and awareness of the risk to the foetus they can be used during labour.

\section{Anticoagulants}

Anticoagulants suppress the thrombo-embolic tendency, which is considerable during pregnancy (British Medical Journal, 1970) with enforced bed rest. The risk to the foetus is probably overemphasized. However, careful control and choice of anticoagulant are important (Hirsh, Cade \& Sulli- van, 1970) and after mobilization its maintenance of questionable value. Twelve patients received anticoagulants (Mendelson, 1952; Stewart, 1952; Brock, Russell \& Randell, 1953; Forssell \& Brunila, 1957; Myers \& Sharpe, 1957; Naden, Jackson \& Murray, 1961; Shapiro et al., 1962; Bedford, 1964; Capra Marzani \& Navazzotti, 1969; Curry \& Quintana, 1970-first admission-and Case 1). Six of these had hypertension (Mendelson, 1952; Stewart, 1952; Brock et al., 1953; Forssell \& Brunila, 1957; and Case 1) and five were delivered by Caesarean section (Mendelson, 1952; Stewart, 1952; Forssell \& Brunila, 1957; Naden et al., 1961; and author). All survived. Only one foetus was lost (Forssell \& Brunila, 1957). 


\section{Method of delivery}

After the acute stage is over one is faced with the question of the safest method of management of the rest of pregnancy. If failure or angina persists it appears that termination of pregnancy is of remarkable therapeutic value. Three such patients (Pfaffenschlager, 1964; Listo \& Björkenheim, 1966; and Case 1) improved after Caesarean section. The patient of Listo \& Björkenheim is unique since infarction occurred during labour; the patient developed severe shock, yet evacuation of the uterus promptly relieved shock.

Eleven patients (Mendelson, 1952; Stewart, 1952; Forssell \& Brunila, 1957; Watson et al., 1960; Lynge, 1961; Naden, Johnson \& Murray, 1961; Bechtel, Lanford \& Mangone, 1963; Pfaffenschlager, 1964; Listo \& Björkenheim, 1966; Fletcher, Knox \& Morton, 1967; and Case 1) were delivered by Caesarean section. Ten survived, one (Lynge, 1961) died a few hours after Caesarean section. The surgical and anaesthetic risks to cardiac patients are small with present techniques. If asymptomatic patients are allowed to progress to labour spontaneously, then, as in other heart diseases the second stage should be assisted. The burden of work of labour should be as short as possible.

\section{Post-partum management}

Early mobilization is to be preferred unless there are cardiological reasons to the contrary. If prolonged bed rest is envisaged then there might be an indication for recommencement of anticoagulant therapy. Case 1 of this series developed thrombophlebitis after Caesarean section and received anticoagulants. The patient of Bechtel et al. (1963) who developed mild thrombophlebitis after Caesarean section did not receive anticoagulants.

Of the patients who sustained a cardiac infarction before labour and made a good recovery from the acute episode before reaching the time of delivery none failed to survive the remainder of pregnancy and labour. It appears, therefore, that once a patient has made a satisfactory recovery from an episode of acute myocardial infarction the remainder of the pregnancy does not have any deleterious effect on the cardiac state. This assumption is supported when one takes account of some of the reported cases (Leff, 1950; Lyons \& Lyons, 1954; Smith \& Gatenby, 1958; Jackson et al., 1965; Rhen \& Salokannel, 1967; Canning, Green \& Mulcahy, 1969) of women who had myocardial infarction before becoming pregnant and surviving it. However, the case of Offergeld (1931) who suffered from angina, died suddenly during the middle of the pregnancy, the case of Bedford (1964) who had had two previous cardiac infarctions developed a third infarction during pregnancy, the case of Curry et al. (1970) who had an infarction before pregnancy had two further infarctions during the same pregnancy and died from the last, and Case 1 of the author was re-admitted for treatment of heart failure after having been discharged well. Coupled with the fact that according to the published cases cardiac infarction during the last trimester and labour is frequently fatal, pregnancy would be contra-indicated in a patient who suffers from ischaemic heart disease.

\section{Acknowledgments}

I am very grateful to Dr S. Oleesky and Miss E. M. Mills for permission to publish Case 1, and to Dr A. Morgan Jones and Dr C. D. R. Pengelly for permission to publish Case 2. 1 am very grateful to Dr Geoftrey Howitt for assistance with preparation of this paper.

\section{References}

ADler, J.J., LASH, S.R. \& BARRASH, M.J. (1968) Myocardial infarction during pregnancy. Illinots Medical Journal, 134, 143.

Antonius, N.A., Izzo, P.A., Hayes, G.W. \& Walsh, C.R. (1955) Myocardial infarction in pregnancy. American Heart Journal, 49, 83.

Bechtel, J.T., LANFoRd, W.S. \& MaNgone, E.L. (1963) Myocardial infarction associated with twin pregnancyo Report of case and Review of Literature. Journal of the Florida Medical Association, 49, 658.

BEDFORD, J.R.D. (1964) Myocardial infarction in pregnanc Journal of Obstetrics and Gynaecology of the Britist Commonwealth, 71, 459.

British Medical Journal (1970) Anti-natal thromboembolism, $1,249$.

Brock, H.J., Russell, N.G. \& Randall, C.L. (1953) Myocardial infarction in pregnancy, report of a case with normal spontaneous delivery 7 months later. Journal of the American Medical Association, 152, 1030.

Brown. A. (1960) Myocardial infarction associated with pregnancy-report of two cases. New England Journal of Medicine, 262, 1163.

Canning, B. St. J., Green, A.T. \& Mulcahy, R. (1969) Coronary heart disease in the puerperium. Journal of Obstetrics and Gynaecology of the British Commonwealth, $76,1018$.

Capra Marzani, P. \& Navazzotti, R. (1969) The myocardial infarction in pregnancy-description of one case. Minerva Medica, 60, 1407.

Committee on Maternal Welfare (1957) Cholecystitis, cholelithiasis and coronary occlusion. New England Journal of Medicine, 256, 574.

CuRRY, J.J. \& Quintana, F.J. (1970) Myocardial infarction with ventricular fibrillation during pregnancy treated by direct current defibrillation with foetal survival. Chest, 58, 82.

Fletcher, E., Knox, E.W. \& Morton, P. (1967) Acute myocardial infarction in pregnancy. British Medical Journal, 3, 586.

Forssell, J. \& Brunila, T. (1957) Cardiac infarction and pregnancy. Acta medica Scandinavica, 157, 387.

Froehlich, J. (1963) Myocardial infarction in a 22-year-old pregnant woman. Case report. Polski Tygodnik Lekarski, $18,21$.

FROEHLICH, J. (1968) A case of myocardial infarction in a pregnant woman. Polish Medical Science and History, 11, 124. 
Ginz, B. (1970) Myocardial infarction in pregnancy. Journal of Obstetrics and Gynaecology of the British Commonwealth, 77, 610.

Goldberger, E. \& Pokress, M.J. (1950) Spontaneous delivery in a woman with myocardial infarction. New York State Journal of Medicine, 50, 95.

Gordon, C.A. (1955) Heart disease as a cause of maternal death. American Journal of Obstetrics and Gynaecology, 69, 701.

Hamilton, B.E. (1947) Report from the cardiac clinic of the Boston lying-in-hospital for the first 25 years. American Heart Journal, 33, 663.

Hamilton, B.E. \& Thompson, K.J. (1941) The Heart in Pregnancy and the Childbearing Age. Wood, Boston.

Hirsh, J. Cade, J.F. \& Sullivan, E.F. (1970) Clinical experience with anticoagulant therapy during pregnancy. British Medical Journal, 1, 270.

Jackson, R.M., Milton, E., Francis, R. \& Payne, Jr. (1965) Anaesthetic management of labor after coronary occlusion. Anaesthesia and Analgesia, Current Researches, Cleveland, 44, 499.

JACOBS, M. \& MORESS, E.J. (1961). Myocardial infarction complicating pregnancy. Journal of Newark Beth Israel Hospital, 12, 216.

Jensen, J. (1938) The Heart in Pregnancy, p. 327. Mosby, St Louis.

JeWeTt, J.F. (1965) Massachussetts Medical Society Committee on Maternal Welfare: Coronary occlusion. New England Journal of Medicine, 272, 1079.

Jones, A.M. (1951) Heart Disease in Pregnancy. Harvey and Blythe, London.

KATZ, H. (1922) About the sudden natural death in pregnancy: during delivery and the puerperium. Archiv. fur Gynaekologie, 115, 283.

KRAWCZUK, A. \& JAKowicki, J. (1965) Two cases of myocardial infarction during the course of labour. Ginekologia Polska, 36, 1183.

LefF, M. (1950) Pregnancy 6 months following coronary occlusion. Personal communication to C. L. Mendelson (1952).

Listo, M. \& BJöRkenheIM, G. (1966) Myocardial infarction during delivery. Acta obstetricia et gynecologica Scandinavica, 45, 268.

LYNGE, B. (1961) Familial hypercholesterolaemia. A case of coronary occlusion in pregnancy. Ugeskrist for Laeger, 123, 449.

Lyons, B.H. \& Lyons, R. (1954) Coronary artery disease in pregnancy. Canadian Medical Association Journal, 71, 267.

MAGNER, D. (1961) Coronary occlusion in labour. Journal of Obstetrics and Gynaecology of the British Commonwealth, 68, 128.

Maternal Health in OHo (1958) Committee on Maternal Health of the Ohio State Medical Association. Maternal deaths involving cardiac disease, Case No. 2. Ohio State Medical Journal, 54, 189.
Mather, H.G., Abbas, T.M. \& Mehta, S.H. (1966) Heart disease in pregnancy: a review of 258 consecutive patients. The Practitioner, 196, 227.

Mendelson, C.L. (1952) Coronary artery disease in pregnancy. American Journal of Obstetrics and Gynaecology, $63,381$.

MUIR, C.S. (1960) Coronary heart disease in seven racial groups in Singapore. British Heart Journal, 22, 45.

MYERS, R.F. \& SHARPE, V.J. (1957) Acute myocardial infarction occurring during pregnancy. Canadian Medical Association Journal, 76(9), 754.

NADEN, R.S. Jr., Johnson, H.F. \& MURRay, E.N. (1961) Myocardial infarction during pregnancy. Journal of the American Medical Association, 178, 659.

OfFERGELD, H. (1931) The assessment of the cardiac performance before and during delivery (a contribution to the interruption of pregnancy in heart disease). Archiv fur Gynaekologie, 146, 533.

OLIVER, M.F. (1970) Oral contraceptives and myocardial infarction. British Medical Journal, 2, 210.

Pantev, I. \& Piperkov, T. (1968) Myocardial infarction in pregnancy. Akusherst vo i Ginekologiia (Sofiia), 7, 158.

Pfaffenschlager, F. (1964) Myocardial infarction and pregnancy. Wiener Klinische Wochenschrift, 76, 297.

Phillips, E. (1962) Myocardial infarction in pregnancy. Journal of the American Medical Association, 181, 63.

Reiss, R. \& Frankenthal, L.E. (1935) Labour in cardiac patients, with report of occurrence of coronary occlusion in pregnancy and labour. American Journal of Obstetrics and Gynaecology, 29, 44.

Rhen, K. \& SAlokannel, J. (1967) Pregnancy and delivery after myocardial infarction. Annales Chirurgiae et Gynaecologiae Fenniae, 56, 385.

ROTHE, J. \& SCHLAWE, W. (1965) The importance of cardiovascular disease in pregnancy. Zeitschift fur Aerstliche Fortbildung, Jena. 59, 1321.

Siegler, A.M., Hoffman, J. \& Bloom, O. (1956) Myocardial infarctiun complicating pregnancy. Obstetrics and Gynaecology, 7, 306.

Shapiro, E., Roxen, R.J., Lederman, B. \& Carey, R.J. (1962) Myocardial infarction in the third trimester of pregnancy. Journal of the American Medical Association, 179, 966.

Smith, W.S. \& GatenBy, P.B.B. (1958) Conservative management of heart disease complicating pregnancy. Irish Journal of Medical Science, 394, 457.

StEWART, H.J. (1952) Cardiac Therapy, p. 491. Hoeber, New York.

Watson, H., Emslie-Smith, D., Herring, J. \& Jill, I.G. (1960) Myocardial infarction during pregnancy and puerperium, Lancet, ii, 523.

WeinReb, H.L., German, E. \& Rosenberg, B. (1957) A study of myocardial infarction in women. Annals of Internal Medicine, 46, 285.

White, P.D., Glendy, R.E. \& Gustafson, P. (1937). Myocardial infarction complicating pregnancy in young woman. Journal of the American Medical Association, 109, 863. 